American J. of Engineering and Applied Sciences 2 (2): 353-359, 2009

ISSN 1941-7020

(C) 2009 Science Publications

\title{
Optimal Location of Static Var Compensator Device for Damping Oscillations
}

\author{
M.W. Mustafa and N. Magaji \\ Faculty of Electrical Engineering, University Technology Malaysia, \\ 81310 Skudai, Jahor Bahru, Malaysia
}

\begin{abstract}
Problem statement: Static Var Compensators (SVC) devices are used to improve voltage and reactive power conditions in AC systems. An additional task of SVC is to increase transmission capacity as result of power oscillation damping. The effectiveness of this controller depends on its optimal location and proper signal selection in the power system network. A residue factor had been proposed to find the optimal location of the SVC controllers to damp out the inter-area mode of oscillations. Approach: The proposed residue factor was based on the relative participation of the parameters of SVC controller to the critical mode. A simple approach of computing the residue factor had been proposed, which combined the linearized differential algebraic equation model of the power system and the SVC output equations. Input-output controllability analyses were used to assess the most appropriate input signals (stabilizing signal) for SVC device. Results: The placements of SVC controller had been obtained for the base case as well as for the critical contingency cases. Conclusion: The effectiveness of the proposed method was demonstrated on 25 bus of south Malaysian power system.
\end{abstract}

Key words: SVC, power system oscillations, linear models, eigenvalues, HSV, RHP zeros and residue factors

\section{INTRODUCTION}

Damping of electromechanical oscillations between interconnected synchronous generators is necessary for a secure system operation. Power System Stabilizers (PSSs) are effective for controlling system oscillations but they are usually designed for damping local electromechanical oscillations while the behaviour of low frequency inter-area oscillations is generally determined by global parameters of larger parts of the power system. The limited influence on inter-area modes, however, leads us to the fact that they may not be considered as the only solution to damp inter-area oscillations. Flexible AC Transmission Systems are being increasingly used to better utilize the capacity of existing transmission systems.

Flexible AC Transmission System (FACTS) is a technology based solution to help the utility industry deal with changes in the power delivery business. A major thrust of FACTS technology is the development of power electric based systems that provide dynamic control of the power transfer parameters transmission voltage, line impedance and phase angle ${ }^{[1]}$.
The Static Var Compensator (SVC), which is a shunt device, provides dynamically variable shunt impedance to regulate the voltage at a bus where it is connected $^{[1,2]}$. Application of SVC device for evaluating system damping using various techniques are reported in the literature ${ }^{[3-9]}$ and the usefulness of damping the oscillations depends on the location of SVC controllers. Several methods have been proposed for the placement of FACTS (SVC) controllers. The proposed method by authors ${ }^{[10-13]}$ considered only static criterion base on improving power transfer, Available Transfer Capability (ATC) and loss minimizations and did not took into account any dynamic criteria for the placement of the SVC controllers.

Kalyan Kumar and Singh ${ }^{[14]}$ used modal controllability index, for effective damping, to find suitable location for damping inter-area mode of oscillations. This method, however, consider the model of the system without and with FACTS device to determine the maximum value of the controllability index corresponding to the most critical mode which consider only the input of the FACTS devices without knowing what is happening in the output of the FACTS devices through observe ability index.

Corresponding Author: Nuraddeen Magaji, Faculty of Electrical, University Technology Malaysia, 81310 Skudai, Jahor Bahru, Malaysia Tel: +60177739011 
The selection of appropriate feedback signal to FACTS controllers and effective tuning for improving the damping controls is an important consideration. According to ${ }^{[3,15,16]}$ the most suitable supplementary input signals are locally measured transmission linecurrent magnitude or locally measured active power. $\mathrm{In}^{[17,18]}$ used generator angular speed as a supplementary input signal.

Farsangi et al. ${ }^{[19,20]}$ proposed a method for selecting suitable feedback signal to FACTS controllers for improving the damping. She used the Minimum Singular Values (MSV), the Right-Half Plane zeros (RHP-zeros), the Relative Gain Array (RGA) and the Hankel Singular Values (HSV) as indicators to find stabilizing signals in the Single-Input Single-Output (SISO) and Multi-Input- Multi-Output (MIMO) systems. But she did not suggest any criterion for placing FACTS controllers.

Sadikovic and Anderson ${ }^{[21]}$ used residue, called location index for effective damping, to find suitable location for damping inter-area mode of oscillations. The authors used only UPFC placement based on only single operating condition.

In this study, a residue has been proposed for optimal placement of SVC controllers. These residues have been calculated for the base case and for appropriate operating conditions, e.g., with the some lines out of service to obtained optimal placement of the SVC. In addition, the best selection of the input signals for SVC device proposed by ${ }^{[19,20]}$ has also been applied in this study extended to practical system that is TNB 25 bus system.

\section{MATERIALS AND METHODS}

Residue: Let us start from the mathematical model a dynamic system expressed in terms of a system of nonlinear differential equations:

$\dot{\mathrm{x}}=\mathrm{F}(\mathrm{x}, \mathrm{t})$

If this system of non-linear differential equations is linearized around an operating point of interest $\mathrm{x}=\mathrm{x}_{0}$, it results in:

$\Delta \dot{\mathrm{x}}=\mathrm{A} \Delta \mathrm{x}(\mathrm{t})$

Assume that an input $\mathrm{u}(\mathrm{t})$ and an output $\mathrm{y}(\mathrm{t})$ of the linear dynamic system (2) have defined:

$\dot{\mathrm{x}}(\mathrm{t})=\mathrm{Ax}(\mathrm{t})+\mathrm{Bu}(\mathrm{t})$

$y(t)=C x(t)$
Considering (3) with Single Input and Single Output (SISO) and assuming $\mathrm{D}=0$, the open loop transfer function of the system can be obtained by:

$$
\begin{aligned}
G(s) & =\frac{y(s)}{u(s)} \\
& =C(s I-A)^{-1} B
\end{aligned}
$$

The transfer function $\mathrm{G}(\mathrm{s})$ can be expanded in partial fractions of the Laplace transform of $\mathrm{y}$ in terms of $\mathrm{C}$ and $\mathrm{B}$ matrices and the right and left eigenvectors as:

$$
\begin{aligned}
G(s) & =\sum_{i=1}^{N} \frac{C \phi_{i} \psi_{i} B}{\left(s-\lambda_{i}\right)} \\
& =\sum_{i=1}^{N} \frac{R_{i j k}}{\left(s-\lambda_{i}\right)}
\end{aligned}
$$

where, $R_{i j k}$ is the residue associated with ith mode, $j$ th output and kth input. $\mathrm{R}_{\mathrm{ijk}}$ can be expressed as:

$\mathrm{R}_{\mathrm{ijk}}=\mathrm{C}_{\mathrm{j}} \mathrm{v}_{\mathrm{i}} \mathrm{w}_{\mathrm{i}} \mathrm{B}_{\mathrm{k}}$

where, $\mathrm{v}_{\mathrm{i}}$ and $\mathrm{w}_{\mathrm{i}}$ denote the right and left eigenvectors, respectively associated with the ith eigenvalue.

This can be expressed in terms of mode controllability arid observability. The controllability of mode $\mathrm{i}$ from the kth input is given by:

$\mathrm{CI}_{\mathrm{ik}}=\left|\mathrm{w}_{\mathrm{i}} \mathrm{B}_{\mathrm{k}}\right|$

The measure of mode observability of mode $i$ from output $\mathrm{j}$ is given by:

$$
\operatorname{Obsv}_{\mathrm{ij}}=\left|\mathrm{C}_{\mathrm{j}} \mathrm{v}_{\mathrm{i}}\right|
$$

It is clear that:

$\left|\mathrm{R}_{\mathrm{ijk}}\right|=\left|\mathrm{C}_{\mathrm{j}} \mathrm{v}_{\mathrm{i}} \mathrm{w}_{\mathrm{i}} \mathrm{B}_{\mathrm{k}}\right|=\operatorname{obsv}_{\mathrm{ij}} * \operatorname{cont}_{\mathrm{ik}}$

Each term in the denominator, $R_{i j k}$, of the summation is a scalar called residue. The residue $R_{i j k}$ of a particular mode $\mathrm{i}$ give the measure of that mode's sensitivity to a feedback between the output $y$ and the input $\mathrm{u}$; it is the product of the mode's observability and controllability. It can be proven ${ }^{[22]}$ that when the feedback control is applied, the shift of an eigenvalues can be calculated by:

$\Delta \lambda_{\mathrm{i}}=\mathrm{R}_{\mathrm{i}} \mathrm{H}\left(\lambda_{\mathrm{i}}\right)$ 
For the mode of the interest, residues at all locations have to be calculated. The largest residue then indicates the most effective location of FACTS device $^{[23]}$.

\section{Calculation for model residue:}

Dynamic model of the system: Each generator of the test systems is equipped with the AVR Type III which is the simplest AVR model that can be used for rough stability evaluations ${ }^{[24]}$. The generator is described by six order non-linear mathematical model while exciter by third order. The sixth order model of generator is obtained assuming the presence of a field circuit and an additional circuit along the $\mathrm{d}$-axis and two additional circuits along the q-axis. The generator state variables are $\left(\delta, \omega, \mathrm{e}_{\mathrm{q}}^{\prime}, \mathrm{e}_{\mathrm{d}}^{\prime}, \mathrm{e}_{\mathrm{q}}^{\prime}\right.$ and $\left.\mathrm{e}_{\mathrm{d}}^{\prime \prime}\right)$ while exciter has the following state variables $\left(\mathrm{v}_{\mathrm{m}}, \mathrm{v}_{\mathrm{r}}, \mathrm{v}_{\mathrm{f}}\right)^{[24]}$. The state variables are also defined in M.A Pai ${ }^{[21]}$.

Model based on numerical linearization: In Power system analysis toolbox program, the test system linearization is done numerically as explain:

$$
\begin{aligned}
& \dot{x}=f(x, u) \\
& 0=g(x, u) \\
& y=h(x, u)
\end{aligned}
$$

Linearizing Eq. 10-12 around the equilibrium point gives the following Eq. 13- 15:

$\Delta \dot{\mathrm{X}}=\mathrm{A} \Delta \mathrm{X}+\mathrm{B} \Delta \mathrm{U}$

$0=\mathrm{P} \Delta \mathrm{X}+\mathrm{Q} \Delta \mathrm{U}$

$\Delta \dot{\mathrm{Y}}=\mathrm{C} \Delta \mathrm{X}+\mathrm{D} \Delta \mathrm{U}$

Where, A, B, P, Q, C and D are the matrix of partial derivatives in 13- 15 evaluated at equilibrium points. $\operatorname{In}^{[24]}$ those equilibrium points or initials conditions are obtained after power flow simulation of the test system. Where:

$$
\begin{aligned}
& \Delta \mathrm{X}=\left[\Delta \delta_{\mathrm{i}}, \Delta \omega_{\mathrm{i}}, \Delta \mathrm{e}_{\mathrm{di}}^{\prime}, \Delta \mathrm{e}_{\mathrm{di}}^{\prime}, \Delta \mathrm{e}_{\mathrm{qi}}^{\prime}, \Delta \mathrm{e}_{\mathrm{qi}}^{\prime \prime}, \Delta \mathrm{v}_{\mathrm{mi}}, \Delta \mathrm{v}_{\mathrm{ri}}, \Delta \mathrm{v}_{\mathrm{fi}}\right] \\
& \Delta \mathrm{U}=\left[\Delta \mathrm{I}_{\mathrm{di}}, \Delta \mathrm{I}_{\mathrm{qi}}, \Delta \mathrm{I}_{\mathrm{did}}, \Delta \theta_{\mathrm{i}}, \Delta \mathrm{V}_{\mathrm{i}}, \Delta \theta_{\mathrm{k}}, \Delta \mathrm{V}_{\mathrm{k}}\right]
\end{aligned}
$$

Iq and Id are the quadrature and direct axis components of the stator current, respectively, while $\mathrm{V} \angle \theta$ is the complex bus voltage.
Residue factor for SVC device: Let an SVC, with susceptance $B_{\text {svci }}$, be placed at bus $i$. The reactive power injected into the bus $\left(\mathrm{Q}_{\mathrm{svci}}\right)$ is a function of $\mathrm{SVC}$ susceptance:

$\mathrm{Q}_{\mathrm{svci}}=\mathrm{B}_{\mathrm{SvC}} \mathrm{V}_{\mathrm{i}}^{2}$

where, $\mathrm{Q}_{\text {svci }}$ and $\mathrm{V}_{\mathrm{i}}$ are the reactive power injected and voltage at bus $i$, respectively. Considering initial value of $\mathrm{B}_{\text {svci }}$ as zero and linearizing (18), we obtain:

$\Delta \mathrm{Q}_{\mathrm{svci}}=\mathrm{V}_{\mathrm{i}}^{2} \Delta \mathrm{B}_{\mathrm{SVC}}$

Combining (14) and (19) provides:

$\mathrm{P} \Delta \mathrm{X}+\mathrm{Q} \Delta \mathrm{U}+\mathrm{L} \Delta \mathrm{B}_{\mathrm{svc}}=0$

Where matrix $\mathrm{L}$ contains partial derivatives of power balance equations at all the buses with respect to the susceptance, provided by the SVC, initially assumed to be placed at all the buses. Solving (13) and (20), we obtain:

$\Delta \dot{\mathrm{X}}=\left(\mathrm{A}-\mathrm{BQ}^{-1} \mathrm{P}\right) \Delta \mathrm{X}+\left(-\mathrm{BQ}^{-1} \mathrm{~L}\right) \Delta \mathrm{B}_{\mathrm{svc}}$

Equation 21 can be rewritten as:

$\Delta \dot{\mathrm{X}}=\mathrm{A}^{\prime} \Delta \mathrm{X}+\mathrm{L}^{\prime} \Delta \mathrm{B}_{\mathrm{svc}}$

where, $\mathrm{w}$ is the left eigenvector of matrix $A^{\prime}$ corresponding to the kth mode.

The controllability index of SVC placed at the ith bus to the kth mode can be defined as given in Eq. 7:

$\mathrm{CI}_{\mathrm{i}}=\mathrm{w}_{\mathrm{k}}^{\mathrm{T}} \mathrm{L}_{\mathrm{i}}^{\prime}$

To get the observability index of SVC, substitute Eq. 20 in 15 :

$\Delta \mathrm{Y}=\left(\mathrm{C}-\mathrm{DQ}^{-1} \mathrm{P}\right) \Delta \mathrm{X}+\left(-\mathrm{DQ}^{-1} \mathrm{~L}\right) \Delta \mathrm{B}_{\mathrm{svc}}$

Therefore Eq. 24 can be written as:

$\Delta \mathrm{Y}=\mathrm{C}^{\prime} \Delta \mathrm{X}+\mathrm{D}^{\prime} \Delta \mathrm{B}_{\mathrm{svc}}$

where, E' is an output matrix with SVC device. The observability index of SVC placed at the ith bus to the kth mode can be defined as given in Eq. 8:

$\mathrm{OI}_{\mathrm{i}}=\mathrm{C}_{\mathrm{i}}^{\prime} \mathrm{v}_{\mathrm{k}}$ 
Therefore the product of Eq. 25 and 26 will give the Residue factor defined by Eq. 9.

Selection of feedback signals for SVC device: Right Hand Plane (RHP) Zeros Consider an open loop system with a transfer function from output $y_{i}$ to input $u_{i}$ as $G(s)$. Where:

$$
\mathrm{G}(\mathrm{s})=\frac{\mathrm{b}(\mathrm{s})}{\mathrm{a}(\mathrm{s})}
$$

There may be a finite values of $s$ for which $b(s)=0$ and these are called the zeros of $G(s)$, likewise the values of $s$ that make $a(s)=0$ are called pole of $G(s)$, let these zeros be donated as $z_{i}$ and poles be $p_{i}$.

If the open loop system is applied a constant controller $\mathrm{Kp}$, the closed loop system with negative feedback can be express as:

$$
\mathrm{G}_{\text {closed }}(\mathrm{s})=\frac{\mathrm{K}_{\mathrm{p}} \mathrm{b}(\mathrm{s})}{\mathrm{a}(\mathrm{s})+\mathrm{b}(\mathrm{s}) \mathrm{K}_{\mathrm{p}}}
$$

From Eq. 29 the locations of zeros that is $\mathrm{zi}$ is maintained while poles location change from $\mathrm{a}(\mathrm{s})=0$ that is pi to $[\mathrm{a}(\mathrm{s})+\mathrm{b}(\mathrm{s}) \mathrm{Kp}]=0$ by the feedback signal. From the same Eq. 29 we have the following observations:

- If the feedback gain increases, the closed loop poles will move from open loop poles to open loop zeros, this may lead to instability ${ }^{[20,25]}$

- If the feedback gain decreases, the closed loop poles will move to open loop poles

From observation number one, if the open loop zeros are in right half plane then the closed loop poles can change from stable pole to unstable and can lead to pole zero cancellation. Therefore, the selection of feedback signal should be made in such a way that the closed loop system has a minimum number of the RHPzeros, which are required not to lie within the closed loop bandwidth ${ }^{[19,25]}$.

\section{Criteria for optimal placement of svc device:}

Dynamic criterion based on residue: The FACTS controllers have been placed on the basis of the maximum value of the residue corresponding to the most critical mode. In this study, only inter-area modes of oscillations have been considered.

SVC has been placed at a bus having maximum value of the residue.

For validating the placement of SVC device for various operating conditions, few critical single-line (N-1) contingency cases were considered and the residue factors were calculated for three critical contingency cases. The critical contingencies were selected on the basis of dynamic contingency selection base on damping factor ${ }^{[26,27]}$.

The Damping factor $\varsigma$ which is defined as the damping ratio of the critical inter-area rotor angle mode in the system under an operating condition is smallsignal secure if $\varsigma \geq \varsigma_{\mathrm{C}}$ where $\varsigma_{\mathrm{C}}$ is the damping threshold (normally in the range of $3-5 \%)^{[28]}$. But in this study $\varsigma_{C}$ is referred to a base case critical inter-area mode damping factor. If the damping factor of post contingency case is less than the base case damping factor or power flow diverges, then the case is selected as a severe case.

Procedure: Contingency assessment for small signal stability analysis involves the following steps:

- Perform free fault power flow and eigenvalue analysis

- Determine inter area mode from the eigenvalue of the system

- Performing damping analysis on the power flow condition base on inter area mode

- $\quad$ Select contingency base on overloaded lines

- Repeat step (1-3) for each contingency selected

\section{RESULTS}

The effectiveness of the proposed method was tested on TNB 25 bus system of south Malaysian network. The results for the system are presented as follows:

TNB 25 bus system: The system consists of 12 generators, five consumers and 37 branches with generator 3 taken as reference generator. The equivalent power system of south Malaysian peninsular is depicted in Fig. 1. Modal analysis shows that, in the base case, the critical mode that is an interarea mode has an eigenvalues of $-0.11223 \pm \mathrm{j} 6.2356$ and damping ratio of 0.017995 , which is relatively low.

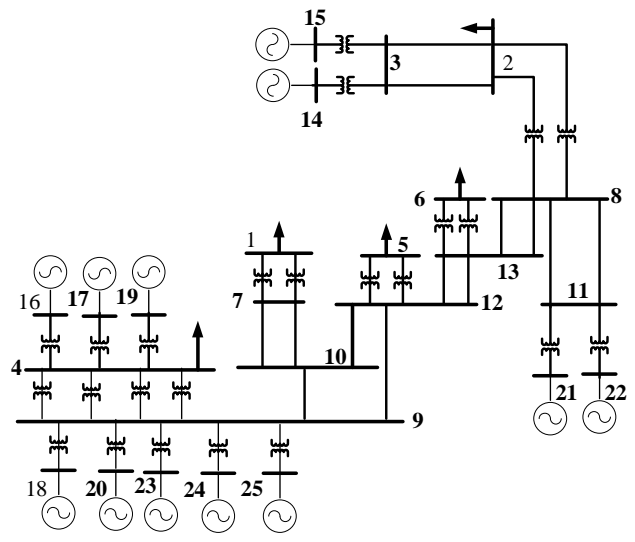

Fig. 1: 25-Bus equivalent of south Malaysian power system 
Am. J. Engg. \& Applied Sci., 2 (2): 353-359, 2009

Table 1: Placement of SVC using residue factor techniques with different operating conditions for TNB 25 Bus system

\begin{tabular}{llllll}
\hline & Base case & Line & Line & & \\
Bus & $7-10$ outage & $12-13$ outage & $8-13$ outage & Line & Average \\
\hline 1 & 0.0158 & 0.0050 & 0.0027 & 0.00007 & 0.0059 \\
2 & 0.0055 & 0.0017 & 0.0043 & 0.00080 & 0.0031 \\
3 & 0.0126 & 0.0050 & 0.0037 & 0.00001 & 0.0053 \\
4 & 0.0005 & 0.0024 & 0.0108 & 0.00040 & 0.0036 \\
5 & 0.0169 & 0.0089 & 0.0078 & 0.00010 & 0.0084 \\
6 & 0.0086 & 0.0054 & 0.0129 & 0.00040 & 0.0068 \\
7 & 0.0045 & 0.0092 & 0.0051 & 0.00021 & 0.0048 \\
8 & 0.0015 & 0.0063 & 0.0066 & 0.00150 & 0.0040 \\
9 & 0.0048 & 0.0040 & 0.0068 & 0.00140 & 0.0043 \\
10 & 0.0019 & 0.0015 & 0.0060 & 0.00030 & 0.0024 \\
11 & 0.0021 & 0.0080 & 0.0072 & 0.00180 & 0.0048 \\
12 & 0.0080 & 0.0045 & 0.0065 & 0.00050 & 0.0049 \\
13 & 0.0047 & 0.0021 & 0.0034 & 0.00100 & 0.0028 \\
\hline
\end{tabular}

Table 2: (N-1) dynamic critical contingency

\begin{tabular}{|c|c|c|c|c|c|}
\hline \multicolumn{2}{|c|}{ Line outage } & Eigenvalues & Damping & Freq. & Ranking \\
\hline \multicolumn{2}{|c|}{ Base case } & $-0.11223 \pm j 6.2356$ & 0.017995 & 0.99259 & \\
\hline 8 & 13 & $-0.11152 \pm j 6.2443$ & 0.017857 & 0.99396 & 1 \\
\hline 12 & 13 & $-0.1117 \pm \mathrm{j} 6.2422$ & 0.017891 & 0.99396 & 2 \\
\hline 2 & 3 & $-0.11187 \pm j 6.2399$ & 0.017925 & 0.99326 & 3 \\
\hline 8 & 11 & $-0.11195 \pm j 6.2388$ & 0.017941 & 0.99310 & 4 \\
\hline 7 & 10 & $-0.11196 \pm j 6.2387$ & 0.017943 & 0.99308 & 5 \\
\hline 9 & 10 & $-0.11222 \pm j 6.2358$ & 0.017993 & 0.99262 & 6 \\
\hline 10 & 12 & $-0.11222 \pm j 6.2356$ & 0.017993 & 0.99262 & 7 \\
\hline
\end{tabular}

\section{DISCUSSION}

Placement: The Residue Factors for weakly damped inter-area mode, computed for SVC are given in Table 1. All the buses, excluding generator buses are considered. It is observed from Table 1 that bus 5 has the maximum residue factor value for placement of SVC device on base case but for validating the placement, the critical contingency ranking is obtained and listed in Table 2 according eigenvalue concepts explained previously. The residue factors were computed for three different critical contingency cases only and are shown in Table 1 also. It can be seen that bus 7 and bus 6 has maximum residue factors for the outages of line 7-10 and 12-13 respectively. While for the outage of line 8-13 bus 9 has the highest residue factor. After finding the average of the residue factor computed for all the cases, bus 5 has been found to be the suitable location for the SVC placement

A Hankel singular value (HSV) analysis was carried out to find the suitable feedback signals for the SVC controllers ${ }^{[25]}$. The speed deviation of generator G14 with respect to G17 is found to be the best signal for SVC supplementary controller.

Performance evaluation of the system: To test the effective location a supplementary controller is designed for the SVC using the Loop shaping techniques ${ }^{[22]}$. Three-phase fault was applied at bus 17 that was cleared $50 \mathrm{~ms}$ later. The impacts on damping
Table 3: Damping for TNB 25 bus with SVC and withoutSVC

\begin{tabular}{llll}
\hline & Real. & Imag. & Damping \\
\hline NO SVC & -0.11195 & 6.2387 & 0.01794 \\
SVC & -0.11297 & 6.2273 & 0.01810 \\
\hline
\end{tabular}

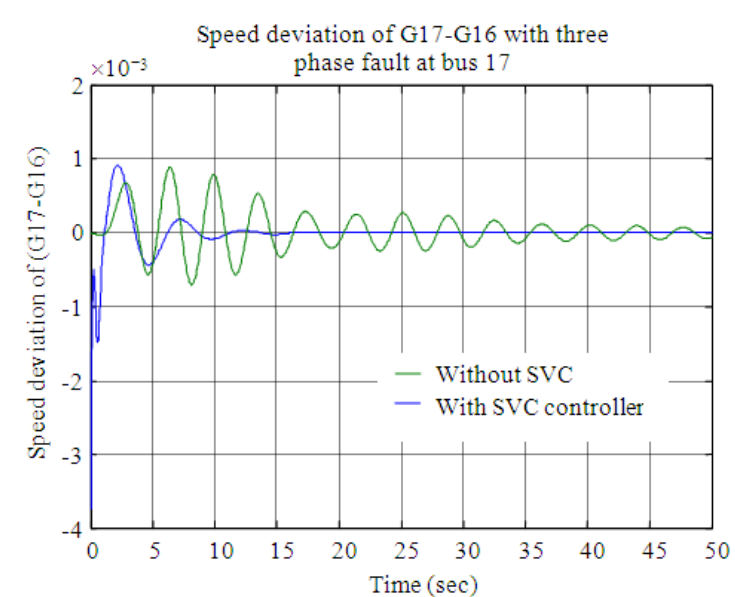

Fig. 2: Speed deviation of (G17-16) response with three phase fault

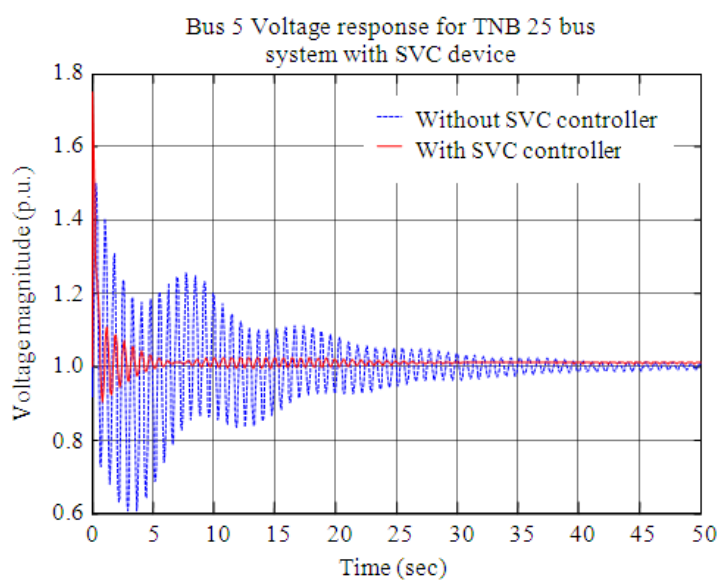

Fig. 3: Bus 5 voltage responses with three phase fault

of the critical inter-area mode with and without SVC controllers are given in Table 3. It can be seen that with the placement of SVC controllers, the system damping improved significantly. The step input was applied to the voltage reference of SVC device to observe the impact of SVC controllers on the inter-area mode damping, generator G17 oscillates against G19, G23 and, G24. It is observed from Fig. 2 that the speed deviation of generator G17 continues to oscillate without SVC device. The speed deviation oscillations are damped out after the placement of SVC device with the controller and settles down in about 11s. The remaining responses of the system are shown in Fig. 3-4. 


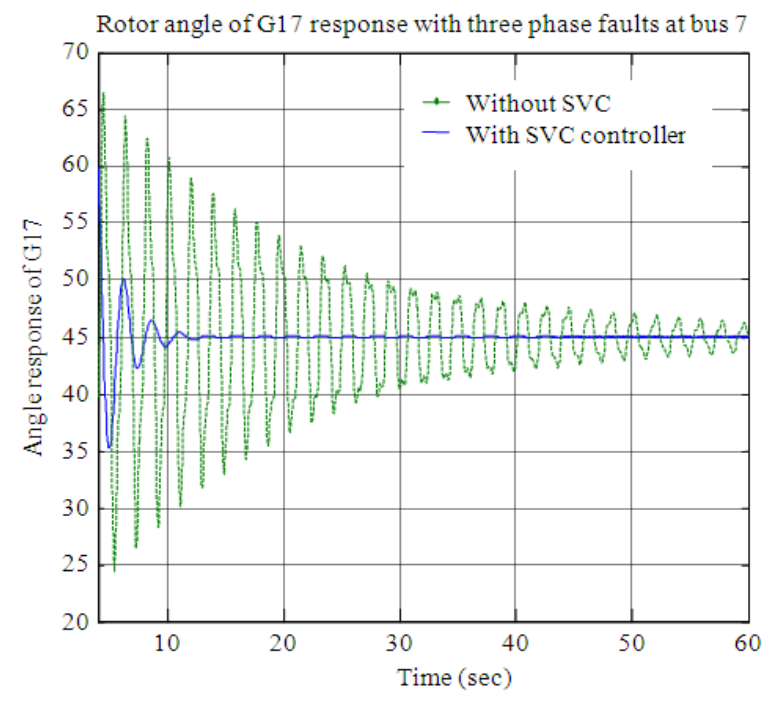

Fig. 4: Rotor angle of G17 response with three phase fault

\section{CONCLUSION}

Residue factor for the placement of SVC device have been found corresponding to a critical inter-area mode for reduce model of 25 bus south Malaysian power system.

These factors have been computed for the base case and for dynamic critical contingencies and the SVC device have been placed at a base having average value of the residue factor.

The time domain simulations have shown that the inter-area mode is significantly improvement in the damping of oscillations with the SVC device when placed at the best location using the proposed residue factor. All the simulations were done with PSAT toolbox in Matlab environment.

\section{ACKNKNOWLEDGMENT}

The researchers would like to express their appreciation to the University Teknologi Malaysia (UTM) and Ministry of Science Technology and Innovation (MOSTI) for funding this research.

\section{REFERENCES}

1. Kazemi, A. and H. Andami, 2004. FACTS devices in deregulated electric power systems: Review. Proceeding of the IEEE International Conference on Electric Utility Deregulation, Restructuring and Power Technologies, Apr. 2004, Hong Kong, pp: $337-342$.

http://ieeexplore.ieee.org/Xplore/login
2. Messina, A.R. and M.N., 1999. An efficient placement algorithm of multiple controllers for damping power system oscillations. Proceeding of the IEEE Power Engineering Society Summer Meeting, July 18-22, IEEE Xplore Press, Edmonton, Alta, Canada, pp: 1280-1285. DOI: 10.1109/PESS.1999.787507

3. Leirbukt, A.B. et al., 1999. Damping control design based on time-domain identified models. IEEE Trans. Power Syst., 14: 172-178. DOI: 10.1109/59.744511

4. Chaudhuri, B. and B.C. Pal, 2004. Robust damping of multi swing modes employing global stabilizing signals with a TCSC. IEEE Trans. Power Syst., 19: 499-505. DOI: 10.1109/TPWRS.2003.821463

5. Larsen, E.V., J.J. Sanchez-Gasca and J.H. Chow, 1995. Concepts for design of facts controllers to damp power swings. IEEE Trans. Power Syst., 10: 948-955. DOI: $10.1109 / 59.387938$

6. Fan, L. and A. Feliachi, 2001. Robust TCSC control design for damping inter-area oscillations. Proceeding of the IEEE Summer Meeting on Power Engineering Society, July 15-19, IEEE Xplore Press, Vancouver, BC., Canada, pp: 784-789. DOI: 10.1109/PESS.2001.970149

7. Bamasak, S.M., 2005. FACTS-based stabilizers for power system stability enhancement. in: electrical engineering. King Fahd University of Petroleum and Minerals, Dahran, Saudi Arabia, pp: 200. https://eprints.kfupm.edu.sa/9786/1/9786.pdf

8. Haque, M.H., 2006. Damping improvement by FACTS devices: A comparison between STATCOM and SSSC. Elect. Power Syst. Res., 76: 865-872. DOI: 10.1016/j.epsr.2005.11.001

9. Chow, J.H. and E.V.L., 1987. SVC control design concepts for system dynamic performance. Proceeding of the Application of Static VAR Systems for System Dynamic Performance, IEEE Special Publication No. 87TH0187-5-PWR pp: 53-36.

10. Singh, S.N. and A.K. David, 2000. Congestion management by optimizing FACTS device location. Proceedings of the International Conference on Electric Utility Deregulation and Restructuring and Power Technologies, Apr. 4-7, London, UK.

11. Verma, K.S., S.N. Singh and H.O. Gupta, 2001. Location of unified power flow controller for congestion management Electric power congestion management. Elect. Power Res., 58: 89-96. DOI: 10.1016/S0378-7796(01)00123-7 
12. Haque, M.H., 2000. Optimal location of shunt FACTS devices in long transmission lines. Proceedings on Generation Transmission and Distribution, July 2000, IEEE Xplore Press, USA., pp: 218-222. DOI: 10.1049/ip-gtd:20000412

13. Singh, S.N. and A.K. David, 2000. Placement of FACTS devices in open power market. Proceedings of the 5th International Conference on Advances in Power System Control, Operation and Management, Oct. 3-Nov. 1, IEEE Xplore Press, Hong Kong, pp: 173-177. http://ieeexplore.ieee.org/xpl/freeabs_all.jsp?arnum ber $=950290$

14. Kalyan Kumar, B., S.N. Sing and S.C. Srivastava, 2007. Placement of FACTS controllers using modal controllability indices to damp out power system oscillations. IET Generat. Transmiss. Distribut., 1: 209-217. DOI: 10.1049/ietgtd:20050529

15. Mithulananthan, N., C.A. Canizares, J. Reeve and G.J. Rogers, 2003. Comparison of PSS, SVC and STATCOM controllers for damping power system oscillations. IEEE Trans. Power Syst., 18: 786-792. DOI: 10.1109/TPWRS.2003.811181

16. Bikash Pal and B. Chaudhuri, 2005. Robust Control in power Systems. In: Power Electronics and Power Systems Series, Stankovic, M.A.P.A.A. (Ed.). Springer, USA., ISBN: 10: 038725949X, pp: 190.

17. Lee, S. and C.C. Liu, 1994. An output feedback static var controller for the damping of generator oscillations. Elect. Power Syst. Res., 25: 9-16. http://cat.inist.fr/?aModele=afficheN\&cpsidt=4201115

18. Zhou, E.Z., 1993. Application of Static Var Compensators to Increase Power System. IEEE Trans. Power Syst., 18: 655-661. DOI: 10.1109/59.260815

19. Farsangi, S., M.M., Y.H. and Y. Lee, 2004. Choice of FACTS device control input for damping interarea oscillations. IEEE Trans. Power Syst., 19: 1135-1143. DOI: 10.1109/TPWRS.2003.820705
20. Farsangi, S.M.M., Y.H. and Y. Lee, 2005. Selection of Supplementary Input Signals for STATCOM to Damp Inter-Area Oscillations in Power Systems. Proceeding of the IEEE Power Engineering Society General Meeting, June 2005, pp: 3068- 3073. DOI: 10.1109/PES.2005.1489745

21. Sadikovic, R., P.K. and G. Andersson, 2005. Application of FACTS Devices for Damping of Power System Oscillations. Proceeding of the IEEE Power Tech St. Petersburg, June 27-30, Russia, pp: 1-6.

22. Lijun Ca, 2004. Robust Coordinated Control of FACTS Devices in Large Power Systems. Published by Logos Verlag, Berlin,. ISBN: 3-83250570-9.

23. Sadikovi, C.R., 2006. Use of FACTS devices for power flow control and damping of oscillations in power systems. PhD Dissertation Swiss Federal Institute Technol. Zurich. www.eeh.ee.ethz.ch/uploads/tx_ethpublications/eth -diss-16707.

24. Milano, F., 2007. Documentation for PSAT version 2.0.0 $\beta$. http://www.power.uwaterloo.ca/ fmilano/psat.htm

25. Maciejowski, J.M., 1989. Multivariable Feedback Design. Addison-Wesley Publishing Company Inc., Wokingham, England, ISBN: 0201182432, pp: 424.

26. Albuyeh, F., A. Bose and B. 1982. Heath, Reactive Power Considerations in Automatic Contingency Selection. IEEE Trans. Power Apparatus Syst., 101: 107-112. DOI: 10.1109/TPAS.1982.317327

27. Hsu, C.L.C., 1990. A new approach to dynamic contiingency selection. IEEE Trans. Power Syst., 5: 1524-1528. DOI: 10.1109/59.99408

28. Chung, C.Y., L.W.F. Howell and P. Kundur, 2004. Generation rescheduling methods to improve power transfer capability constrained by smallsignal stability. IEEE Trans. Power Syst., 19: 1524-1530. DOI: 10.1109/TPWRS.2003.820700 